\title{
A CONSTRUÇÃO MIDIÁTICA DO PRECONCEITO: UM CASO DE CONTRADIÇÃO NO JORNALISMO ESPORTIVO
}

Joã॰ Kogawa*

https://orcid.org/0000-0001-8285-9932

Renan Mazzola**

(D) https://orcid.org/0000-0002-4124-3522

Como citar este artigo: KOGAWA, J.; MAZZOLA, R. A construção midiática do preconceito: um caso de contradição no jornalismo esportivo. Todas as Letras - Revista de Lingua e Literatura, São Paulo, v. 23, n. 1, p. 1-13, jan./abr. 2021. DOI 10.5935/ 1980-6914/eLETLL2113225

Submissão: março de 2020. Aceite: janeiro de 2021.

Resumo: Este artigo tem como objetivo analisar as contradições enunciativas presentes na mídia com relação ao discurso de aliança. Esse discurso será problematizado por meio dos pressupostos teóricos da Análise do Discurso. Compomos um corpus de enunciados (re)produzidos pela mídia no contexto de duas polêmicas: 1. o caso de racismo contra o goleiro Aranha, em 2014; 2. o caso mais recente, em que o mesmo goleiro foi construído midiaticamente como culpado de homofobia, em 2017.

Palavras-chave: Jornalismo esportivo. Análise do discurso. Construção midiática. Enunciado dividido. Formação discursiva. 


\section{INTRODUÇÃO}

ste trabalho investiga contradições no discurso de aliança (COURTINE, - 2009) em uma construção midiática ${ }^{1}$. A homogeneização de grupos sociais promovida pelo termo minoria(s) ${ }^{2}$ muitas vezes produz um efeito de inequivocidade ("deve-se dizer/apoiar uma causa e tudo o que com ela se identifica porque é próprio das minorias") característico do funcionamento do discurso de aliança. No entanto, a homogeneidade mais ou menos admitida promovida por esse discurso, por vezes, faz parte de um ritual ideológico que torna impensada a possibilidade de separação, cisão e afastamento de orientações diversas em seu próprio interior. Isto é, a existência mesma de uma expectativa de união inquebrantável entre duas posições distintas e fortuitamente convergentes, não raro, ofusca o que pode falhar (PÊCHEUX, 1997) no discurso de aliança.

Não entendemos falha como erro, incoerência, absurdo etc., mas como a evidência linguística da ação do inconsciente, tal como propõe Pêcheux (1997, p. 300): “[...] os traços inconscientes do significante não são jamais 'apagados' ou 'esquecidos', mas trabalham, sem se deslocar, na pulsação sentido/non sens do sujeito dividido". Essa falha no discurso de aliança apresenta como sintoma os enunciados divididos (COURTINE, 2009), que servem como materialidade do equívoco em exercício.

Nosso corpus é composto por uma série de enunciados - falas proferidas pelo goleiro Aranha e jornalistas que comentam esses dizeres - (re)produzidos na/ pela mídia no cenário de duas polêmicas ocorridas em momentos distintos da história recente do Brasil. No primeiro cenário, temos a articulação entre a fala do goleiro Aranha e sua repercussão midiática como denúncia do racismo em 2014. No segundo, temos a articulação entre a fala do goleiro Aranha e sua repercussão midiática como manifestação de homofobia em 2017. Essas polêmicas suscitaram a seguinte pergunta: que condições político-ideológicas regulam a equivocidade dos dizeres midiatizados do goleiro Aranha que evidenciam o racismo, de um lado, e a homofobia, de outro? Partimos da hipótese de que a unicidade do discurso de aliança - simulacro da união entre minorias - é um efeito ideológico do nosso tempo - intensificado na/pela mídia -, e não uma verdade incontestável na homogeneidade das causas minoritárias. As falas do goleiro Aranha e a ele associadas materializam o que falha no efeito homogeneizante do discurso de aliança.

\section{O ACONTECIMENTO: CONDIÇões DE EMERGÊNCIA DE ENUNCIADOS MIDIÁTICOS}

Em 28 de agosto de 2014, Grêmio e Santos enfrentaram-se pelas oitavas de final da Copa do Brasil. Aos 37 minutos do primeiro tempo, o Santos marcou o primeiro gol e, aos 44, ampliou a vantagem. Ao final, o time paulista saiu vencedor.

1 Embora saibamos que o texto midiático engloba regimes de visibilidade, recortaremos apenas os enunciados linguísticos por entender que, para o propósito deste artigo, os aspectos não verbais não são essenciais.

2 Neste artigo, negros e homossexuais são significados nas/pelas declarações do goleiro Aranha e sua consequente repercussão na mídia em duas temporalidades diferentes (2014 e 2017). A ordem cronológica dos acontecimentos em que recuperamos as falas do goleiro Aranha inicia-se com uma defesa da igualdade racial - contra o preconceito racial sofrido pelo goleiro no ano de 2014 - e termina com uma cobrança ao goleiro, em 2017, por ter proferido declarações discriminatórias em relação aos homossexuais. 
Ao final do segundo tempo, episódios de ofensas racistas tomaram proporção contra o goleiro Aranha. A partir dos 40 minutos, uma torcedora gremista é filmada, com close em seu rosto, no momento em que profere: "Macaco!". Em seguida, outro grupo de jovens gremistas é registrado fazendo gestos que remetem ao comportamento dos macacos. Nesse momento, Aranha gesticula para o juiz e para os repórteres em campo, indignado, para que filmassem o grupo de torcedores e suas provocações. Tem início, a partir disso, a cobertura midiática:

(1) Globo Esporte 3

Racismo de grupo de gremistas tira Aranha do sério: "Sou negão, sim!". Revoltado, goleiro afirma que foi chamado de "macaco" e "preto fedido" na vitória santista contra o Grêmio, por 2 a 0 , em Porto Alegre.

(2) O Globo.com ${ }^{4}$

Goleiro do Santos é vítima de racismo em Porto Alegre. Aranha teria sido xingado de "negro fedido" e "macaco" na vitória do time por 2 a 0.

(3) $\mathrm{ESPN}^{5}$

Aranha é chamado de "macaco" por torcida do Grêmio.

Apesar de as ofensas proferidas pelos torcedores terem sido noticiadas com certo anonimato ou com a omissão do agente nas manchetes do dia - designando os agressores como "grupo de gremistas" (1), "teria sido xingado [...] na vitória por 2 a 0" (2), "por torcida do Grêmio" (3) -, esses xingamentos, ao longo das semanas, foram personificados. O preconceito teve rosto e nome próprio: "Patrícia Moreira". Esse rosto em close proferindo "Macaco!", reproduzido sem cessar nas mídias tradicionais e digitais, instaura um processo inquisitório (a população cobrará a acusada; será júri e juiz da causa), além do processo criminal. A torcedora gremista pagou um preço pela exposição, conforme vemos na entrevista ao Fantástico:

\section{(4) Entrevista ao Fantástico ${ }^{6}$}

Patrícia perdeu o emprego, a casa dela foi apedrejada e ela deve depor nessa segunda-feira $\left(1^{\circ}\right)$ na polícia de Porto Alegre.

O caso parecia ter tido seu "final feliz", com a autora das ofensas devidamente julgada e condenada, nos moldes de uma grande narrativa. O ponto final fora colocado e a história acabara ali, não fosse por outros acontecimentos...

Quase três anos depois, o mesmo goleiro Aranha, jogando pelo Campeonato Paulista de Futebol, após a derrota por 1 x 0 para o Palmeiras (que precisava ter ganhado o jogo por três gols de diferença para, ao menos, conseguir levar a partida para os pênaltis), protagoniza outro caso de preconceito. Agora, não como vítima, mas como autor. Após ser perguntado por um repórter a respeito de seus treinamentos e, indiretamente, sobre sua forma física, o goleiro, após a partida em tom que foi interpretado como irônico e infeliz - disse estar bem fisicamente

\footnotetext{
Disponível em: http://globoesporte.globo.com/sp/santos-e-regiao/futebol/times/santos/noticia/2014/08/racismo-grupo-de-gremistastira-aranha-do-serio-sou-negao-sim.html. Acesso em: 23 mar. 2018.

4 Disponível em: https://oglobo.globo.com/esportes/goleiro-do-santos-vitima-de-racismo-em-porto-alegre-13762998. Acesso em: 23 mar. 2018.

5 Disponível em: http://www.espn.com.br/noticia/436034_aranha-e-chamado-de-macaco-por-torcida-do-gremio. Acesso em: 23 mar. 2018.

6 Disponível em: http://g1.globo.com/fantastico/noticia/2014/08/eu-tenho-do-dela-diz-goleiro-aranha-sobre-jovem-que-o-ofendeuem-jogo.html. Acesso em: 23 mar. 2018.
} 
e que a questão sobre a tematização de sua forma física estava associada ao interesse de jornalistas por homens.

(5) SporTV

- Não. Tenho treinado, tenho treinado. É que às vezes tem cara, tem jornalista, que gosta de homem, gosta de homem sarado, gosta de cara que tira a camisa, fica mostrando o abdômen. Respeito a opção sexual de cada repórter, mas estou tranquilo. Estive aqui no Palmeiras, o Palmeiras tem um setor de fisiologia ótimo, sempre estive dentro dos padrões, não sou nenhum garoto, mas sempre tive dentro do padrão limite, aceitável para a prática do futebol, tanto que passei sete anos praticamente em time grande.

O conjunto dos enunciados desse quadro midiático pode ser disposto a partir de dois diferentes momentos: 1. 2014, quando a mídia noticiou o caso de racismo contra o goleiro Aranha, então no Santos; 2. 2017, quando a mídia noticiou a homofobia do goleiro Aranha, então na Ponte Preta, contra um jornalista. Entendemos, dessa forma, que o conjunto dos dizeres das duas épocas não são grupos estanques em si, mas estabelecem, por um efeito de continuidade, um quadro. Como veremos adiante, os dizeres de 2017 retomam constantemente os de 2014 e estabelecem uma espécie de sequência narrativa.

Para a análise que faremos a seguir, dada a diversidade de matérias que acontecimentalizaram o caso, centramos nossa atenção na materialidade dos enunciados inscrita principalmente em duas ocorrências midiáticas. Na primeira, retomamos dizeres proferidos na matéria especial do Fantástico feita em 2014. Nela, o goleiro Aranha é entrevistado e responde a perguntas sobre discriminação e racismo. Na segunda, retomamos dizeres do programa Troca de Passes exibido no Sportv - um canal associado à TV Globo - em 2017. Nessa edição do programa, os comentaristas se posicionam em relação à fala entendida como preconceituosa de Aranha após a derrota da Ponte Preta para o Palmeiras.

\section{DiscuRSO DE ALIANÇA: FORMAÇÃo DISCURSIVA (FD) E ENUNCIADO DIVIDIDO}

Nosso ponto de partida é o que Courtine (2009, p. 128) define como discurso de aliança,

[...] isto é, de uma região do discurso de aparelho em que se encontra regulada a relação com o outro, com o exterior, com o que não é ele mesmo, em vista da constituição de uma aliança ou de uma colaboração política.

O que aqui apresentamos como "relação com o outro" é o discurso de aliança deduzido da FD progressista $\left(\mathrm{FD}_{\text {Prog. }}\right)$ - entendida como espaço de dizibilidade da aceitação das opções, mudanças e diferenças étnicas, sexuais, corporais, politicas, religiosas etc. No quadro dessa FD, observamos a presença de enunciados que materializam uma espécie de imperativo da ordem do "há/deve haver coesão entre dizeres e valores que defendem a aceitação das diferenças". No que concerne aos efeitos dessa regularidade no objeto por nós analisado, essa regra de formação implica um "há/deve haver união" por se tratar de espaços de resistência pró-minoria - convergência político-ideológica entre o antirracismo e a anti-homofobia nos enunciados inscritos no discurso de aliança.

7 Disponível em: http://sportv.globo.com/site/programas/troca-de-passes/noticia/2017/04/aranha-se-irrita-com-pergunta-e-causapolemica-com-insinuacao-sobre-gays.html. Acesso em: 23 mar. 2018. 
Dessa maneira, o discurso de aliança pode ser definido como um conjunto de valores determinados, no interior da $\mathrm{FD}_{\text {Prog. }}$, que regulam o que pode/deve ser dito - e como deve sê-lo - na esfera das causas minoritárias. Margeando essa formação discursiva - interferindo, dialogando e se batendo contra ela como um espaço constitutivo exterior - encontra-se a FD conservadora ( $\left.F D_{\text {Conserv. }}\right)$. Como regime de dizibilidade oposta, esta última é um espaço interdiscursivo de produção e reprodução de sentidos histórico-sociais que, do ponto de vista da $\mathrm{FD}_{\text {Prog.' }}$, deveriam ser rechaçados de acordo com o princípio de aceitabilidade. O efeito ideológico de homogeneidade produzido pelo discurso de aliança - que constrói a ideia de que as minorias estão/devem estar unidas no que dizem e no que pensam - pressupõe um padrão estrutural que gerencia as variáveis das FDs, como se segue:

$$
\mathrm{FD}_{\mathrm{a} .}=[(-\mathrm{x})+(-\mathrm{y})+(-z) \ldots] \text { que se opõe a } \mathrm{FD}_{\mathrm{b} .}=[(+\mathrm{x})+(+\mathrm{y})+(+z) \ldots] .
$$

Essas variáveis $(\mathrm{x}, \mathrm{y}, \mathrm{z})$ podem ser preenchidas pela atualização dos efeitos de sentido de preconceito verificados nos enunciados que midiatizaram a contradição político-ideológica em torno da figura do goleiro Aranha em 2014 e 2017. Nesse sentido, há - à luz do "princípio da aceitabilidade discursiva" (COURTINE, 2009, p. 99) - duas condições de dizibilidade que se impõem às duas FDs distintas:

1. $\mathrm{FD}_{\text {Prog. }}=[(-$ homofobia $)+(-$ racismo $)]$, ou seja, a FD progressista é composta pela negação da homofobia somada à negação do racismo. Em outros termos, essa FD resgataria a ideia de que o progressista tende a não ser nem homofóbico nem racista;

2. $\mathrm{FD}_{\text {Conserv. }}=[(+$ homofobia $)+(+$ racismo $)]$, ou seja, uma FD conservadora composta pela presença da homofobia somada à presença do racismo. Essa FD resgataria, principalmente no debate público e midiático, a ideia de que o conservador tende a ser homofóbico e/ou racista.

Ainda nessa linha de definição das FDs no campo da mídia, o "princípio de exclusão" (COURTINE, 2009, p. 99) define o que não pode/não deve ser dito. Isto é, estaria interditada à $\mathrm{FD}_{\text {Prog. }}$, por exemplo, a atualização $\mathrm{FD}_{\text {Prog. }}=[(+$ homofobia) + (+racismo)]. Isso sistematiza os interditos atinentes à $\mathrm{FD}_{\text {Prog. }}$ : não se pode "ser racista" nem se pode "ser homofóbico". Vale destacar que não estamos com isso dizendo que "todo conservador é racista" ou que "todo progressista é antirracista". Não se trata de rotular posições individuais, mas de propor uma generalização possivel para o horizonte de expectativa que se desenhou na narrativa midiática do caso em tela.

O conceito de enunciado dividido proposto por Courtine (2009) prevê, mais do que a materialidade de uma contradição no nivel intralinguístico, a interferência de uma FD na outra na esfera do discurso. Isso resultaria, na formulação dos enunciados, da materialização do (primado do) interdiscurso no discurso. Conforme Pêcheux (2009, p. 24),

[...] uma formação discursiva é constitutivamente perseguida por seu outro: a contradição motriz não resulta do choque de "corpora contrastados", cada um veiculando a homogeneidade dos antagonistas, mas desse efeito de sobredeterminação pelo qual a alteridade o afeta. 
Essa afirmação de Pêcheux, que integra o prefácio de Análise do discurso politico (COURTINE, 2009), aponta para a possibilidade de intervenção do outro no mesmo. A estrutura que indicamos acima, que visa à homogeneidade das variáveis, passa a prever a alternância no par negativo/positivo:

$$
\begin{aligned}
& \mathrm{FD}_{\mathrm{a} .}=[(-\mathrm{x})+(-\mathrm{y})+(+\mathrm{z}) \ldots] \text { ou } \\
& \mathrm{FD}_{\mathrm{b} .}=[(+\mathrm{x})+(+\mathrm{y})+(-\mathrm{z}) \ldots] .
\end{aligned}
$$

Assim, considerando essas questões, teríamos a possibilidade de estrutura que se segue:

$$
\begin{aligned}
& \mathrm{FD}_{\text {Prog. }}=[(- \text { homofobia })+(+ \text { racismo })] \\
& \text { ou } \\
& \mathrm{FD}_{\text {Prog. }}=[(+ \text { homofobia })+(- \text { racismo })]
\end{aligned}
$$

O discurso de aliança, desse modo, estaria aberto a sofrer invasões e passaria a prever aquilo que não deveria compor os dizeres a ele associados: o espaço de emergência do enunciado antirracista pode ser também o espaço do enunciado homofóbico e vice-versa, não havendo, portanto, nenhuma relação de necessidade na presença de um diante do outro: "Já era hora de começar a quebrar os espelhos" (PÊCHEUX, 2009, p. 26).

\section{ANÁlise do CORPUS: 0 gUE FALHA?}

Em entrevista exibida em 31 de agosto de 2014 no Fantástico, o goleiro Aranha, então no Santos Futebol Clube, fez as seguintes declarações a respeito dos xingamentos racistas que vinham da arquibancada e que ficaram iconizados na figura da torcedora indentificada na mídia como "Patrícia Moreira". Separamos os enunciados (EDOs) do primeiro material analisado por nós nessa entrevista:

EDO1: Aranha: Eles já tavam já, praticamente o jogo todo, né. E aí foi crescendo, foi crescendo. Porque isso aí já é normal, principalmente nesse estádio aí, quando jogam contra o Grêmio ${ }^{8}$.

EDO2: Fantástico: Você já tinha passado por essa situação? Aranha: Aff, centenas, milhares de vezes. No futebol, infelizmente, isso é normal, principalmente, no Sul do pais ${ }^{9}$. Fantástico: No Sul, principalmente... você acha que é pior lá? Aranha: Ah, com certeza. [...] Fantástico: Por que você acha que é pior no Sul do país? Aranha: Não sei. Talvez eles não... não todos, mas muitos lá não se sentem brasileiros. Fantástico: Por que tem muitos brancos? Fantástico: Não... porque eu acho que é a descendência, né? Tanto que, se não me engano, tocava o hino nacional antes das partidas lá e aí, ou eles vaiavam o hino nacional ou não cantavam. E aí, quando cantava o hino do Rio Grande, eles cantavam. E aí, das últimas vezes que eu fui jogar, não teve o hino nacional mais. Então, ano passado eu fui jogar a Copa do Brasil lá e lembro de passar uma propaganda no telão do estádio, uma matéria contra o racismo ${ }^{10}$.

8 Transcrito do primeiro vídeo. Disponível em: http://g1.globo.com/fantastico/noticia/2014/08/eu-tenho-do-dela-diz-goleiroaranha-sobre-jovem-que-o-ofendeu-em-jogo.html. Acesso em: 23 mar. 2018.

9 Declaração do enteado de Aranha na reportagem do Fantástico. Disponível em: http://g1.globo.com/fantastico/noticia/2014/08/ eu-tenho-do-dela-diz-goleiro-aranha-sobre-jovem-que-o-ofendeu-em-jogo.html. Acesso em: 23 mar. 2018.

10 Transcrito do primeiro vídeo. Disponível em: http://g1.globo.com/fantastico/noticia/2014/08/eu-tenho-do-dela-diz-goleiro-aranhasobre-jovem-que-o-ofendeu-em-jogo.html. Acesso em: 23 mar. 2018. 
O primeiro eixo de construção do sentido do racismo ${ }^{11}$ é espacial. A menção ao lugar do acontecimento é responsável pela retomada do discurso separatista $^{12}$ que, não raro, volta a ser mobilizado quando se trata da região Sul do país. O racismo - manifestação conservadora e antiprogressista -, embora não seja uma exclusividade regional, ganha ênfase a partir do dêitico "aî" no EDO1: “[...] isso aí já é normal, principalmente, nesse estádio aí, quando jogam contra o Grêmio". O time - o Grêmio - é construído como o mandante, dono da arena que metonimiza o Estado e as características de uma região fortemente colonizada por alemães, brancos/caucasianos. Ainda nesse eixo, lemos no EDO2: "[...] isso é normal, principalmente, no Sul do país [...]"; "[...] muitos lá não se sentem brasileiros [...]". O termo "principalmente" garante a não exclusividade do racismo à região Sul e a ênfase ao quanto isso acontece ali. Papel duplo cumprido pelo advérbio: totalizante (o Sul, mas não só) e particularizante (em todo lugar e ainda mais no Sul do país). Afinal, a carga dos valores separatistas cumpre seu papel e culmina na negação de símbolos nacionais:

[...] se não me engano, tocava o hino nacional antes das partidas lá e aí ou eles vaiavam o hino nacional ou não cantavam. E aí, quando cantava o hino do Rio Grande, eles cantavam. E aí, das últimas vezes que eu fui jogar, não teve o hino nacional mais (EDO2).

A arena do Grêmio, palco desse "conservadorismo retrógrado", é sintoma de um racismo generalizado:

EDO3: Fantástico: Fora dos estádios você também tem problema? Sofre com o racismo? Aranha: Tem, tem. Isso ai muita gente tem. A gente vale o que tem. Ou o nome que tem. Eu sei que muitas vezes eu não sou aceito, eu sou tolerado. Porque sou o goleiro do Santos, bicampeão mundial. E porque eu tenho um carro bonito, porque eu compro isso, eu compro aquilo. Então muitas vezes eu sou tolerado, não sou aceito. Eu já morei em prédios, minha família está de testemunha, que não me davam nem bom dia ${ }^{13}$.

Ainda no eixo espacial da construção dos sentidos na entrevista, observamos a passagem do mais público e povoado dos espaços para o mais particular e individualizado deles: do estádio, passa-se a focalizar o ambiente fora dele, pois Aranha explicita como o racismo está presente nos lugares em que morou - espaços do lar, da intimidade familiar e da proximidade com os vizinhos. É preciso, diz a doxa então, denunciar também aí os valores que impedem o progresso e a aceitação das diferenças: "Eu já morei em prédios ${ }^{14}$, minha família está de testemunha, que não me davam nem bom dia” (EDO3).

EDO4: Fantástico: Nos estádios, qual seria a punição para que isso não voltasse a se repetir? Aranha: Essa mocinha aí, nunca mais pisar na Arena. Porque

11 Esses enunciados relativos ao acontecimento de 2014 emergem como um dos efeitos da formação discursiva progressista $\left(\mathrm{FD}_{\mathrm{Prog}}\right.$ ) que visa não apenas validar a causa antirracista como também denunciar o conservadorismo. A repercussão da entrevista participa de um processo de justiça em todas as esferas: do tribunal à opinião pública.

12 Por uma questão de delimitação, não trataremos do separatismo. Apenas para esclarecer, referimo-nos ao histórico conjunto de dizeres associados a uma vontade de separação do Sul do resto do Brasil.

13 Disponível em: http://g1.globo.com/fantastico/noticia/2014/08/eu-tenho-do-dela-diz-goleiro-aranha-sobre-jovem-que-o-ofendeuem-jogo.html. Acesso em: 23 mar. 2018.

14 Para um estudo aprofundado de cunho psicanalítico sobre a vida em condomínios, confira a obra de Christian Dunker, Mal-estar, sofrimento e sintoma: uma psicopatologia do Brasil entre muros (2015). 
outras pessoas vão falar "se eu tomar uma atitude dessas, se eu for flagrado, eu nunca mais vou acompanhar o time que eu gosto”. O futebol está caminhando para um lado de empresa, de espetáculo, mas as pessoas que vão assistir têm que se comportar como tal. Eu acho que a principal punição tem que ser essa, da pessoa nunca mais pisar no estádio, em um lugar público, porque ela me xingou ali, mas tinha vários outros negros ali ${ }^{15}$.

Contra a postura retrógrada, a punição: há que se pensar nas medidas adequadas para impedir as manifestações preconceituosas. A interdição do acesso aos estádios é uma das medidas citadas no sentido de fazer da punição um meio para coibir o preconceito no EDO4. No entanto, não basta punir, pois há raízes mais profundas na sustentação do antiprogressismo conservador. O separatismo de uma região é digno de nota, mas não esgota o tom vigilante do progresso que se faz necessário. O olhar estende-se para o âmbito educacional no EDO5 desloca-se da esfera da punição para a da prevenção. Revela-se então um segundo eixo de produção de sentidos do racismo como prática antiprogressista na mídia (o tempo, enquanto figura da tradição):

EDO5: Aranha: [...] nos dias de hoje e até antigamente esse tipo de situação sempre existiu. Sempre foi muito pesado; por escravidão, por muitas coisas. Eu acho que muito se deve também à criação, à educação que se dá. Às vezes tem muitas coisas que a gente aprende não erradamente, mas de maneira distorcida ou só uma parte da verdade, sabe? Muitas coisas que ensinam nas escolas sobre negritude, sobre a nossa cultura negra e a construção do país, são coisas distorcidas. [...] Pra muita gente, os bandeirantes são só heróis. Você vê nome em ponte, em rodovia e tudo mais. Ai você pergunta: você sabe o que foi um bandeirante? Muita gente nem sabe. Ah, porque a princesa Isabel libertou os escravos... mas a gente foi o último país, a gente... sabe? Eu acho que assinou porque se não assinasse o bicho ia pegar. Não tinha mais como. Já tinha quilombo com mais de trinta mil pessoas ${ }^{16}$.

O trecho acima aponta para um efeito de atribuição de responsabilidade a dois agentes sociais na luta contra a perpetuação do racismo: os pais e a escola - notadamente, a disciplina de História. Instaura-se, assim, o sentido de que o racismo é ao mesmo tempo herança familiar - vem "de berço" - e efeito de uma educação equivocada. As escolas, de acordo com o EDO5, não ensinam a verdade (o que prevê uma "verdade" distinta da "mentira" que normalmente seria ensinada), mas uma versão distorcida dos conteúdos. No quadro desse ensino equivocado, destacam-se as narrativas do bandeirante como herói - "Pra muita gente, os bandeirantes são só heróis. Você vê nome em ponte, em rodovia e tudo mais" (EDO5) - e da libertação dos escravos pela princesa Isabel como ato heróico, progressista e humanístico -

Ah, porque a princesa Isabel libertou os escravos... mas a gente foi o último pais, a gente... sabe? Eu acho que assinou porque se não assinasse o bicho ia pegar. Não tinha mais como. Já tinha quilombo com mais de trinta mil pessoas (EDO5).

15 Disponível em: http://g1.globo.com/fantastico/noticia/2014/08/eu-tenho-do-dela-diz-goleiro-aranha-sobre-jovem-que-o-ofendeuem-jogo.html. Acesso em: 23 mar. 2018.

16 Transcrito do primeiro vídeo. Disponível em: http://g1.globo.com/fantastico/noticia/2014/08/eu-tenho-do-dela-diz-goleiro-aranhasobre-jovem-que-o-ofendeu-em-jogo.html. Acesso em: 23 mar. 2018. 
A crítica ao modo como a História seria ensinada é uma forma de questionar essa disciplina em função de um outro lugar de aprendizado de um conteúdo não distorcido:

EDO6: Eu tive a felicidade de aprender muito com o rap, porque esse pessoal, como sempre foi um pessoal sofrido e acusado e agredido. É um pessoal bem informado sobre politica, sobre religião, sobre a sua história, a história do seu país. Como na periferia a gente ouve muito isso, porque é aquilo que está na nossa realidade, eu cresci preparado para esse tipo de situação, diz Aranha ${ }^{17}$.

Ainda no recorte de análise do eixo temporal, percebemos um deslocamento do tempo da tradição para o tempo do novo. Do lugar da educação formal (escola/disciplina de História) para o da informal (cotidiano). O aprendizado não institucional e o cotidiano exigem que se saia dos muros escolares e se recorra à arte. A meia verdade da história tradicional é colocada em xeque à luz do conhecimento prático dos rappers (a verdade da arte): "[...] um pessoal bem informado sobre política, sobre religião, sobre a sua história, a história do seu país" (EDO6).

Como efeito de "fechamento" desse acontecimento, ou seja, após a punição da torcedora do Grêmio, o caso da violência verbal contra o goleiro Aranha teria se inscrito na ordem da história recente do Brasil e participado da "marcha evolutiva do progresso", em que a igualdade e a luta contra o preconceito devem ser uma constante.

Eis que, alguns anos mais tarde, em 2017, na disputa pelo Campeonato Paulista de Futebol, uma declaração - publicada no site SporTV.com em 22 de abril - do goleiro Aranha, agora na Ponte Preta, repercute no programa Troca de Passes. Seguem, abaixo, a declaração do atleta e os comentários que circunscreveram o enunciado de Aranha ${ }^{18}$ em uma FD Conserv. :

(6) SporTV ${ }^{19}$ (SporTV.com, 22 abr. 2017)

Aranha se irrita com pergunta e causa polêmica com "insinuação" sobre gays.

(7) SporTV $^{20}$ (SporTV.com, 22 abr. 2017)

Goleiro da Ponte Preta faz crítica ao dizer que "tem jornalista que gosta de homem", e declaração é considerada infeliz por apresentadores no "Troca de Passes".

Já na manchete e na legenda explicativa de (6) e (7), instaura-se a polêmica: “[...] 'insinuação' sobre gays”, “[...] tem jornalista que gosta de homem” e "[...] declaração considerada infeliz" reativam a memória discursiva ligada ao acontecimento do episódio racista. As notícias causam espanto, afinal, quem tinha boa memória podia se perguntar: "É o mesmo Aranha que foi defendido publicamente por todos numa causa minoritária"?

As câmeras que tudo viram em 2014, que denunciaram a injustiça, o racismo e atualizaram as regras da $F D_{\text {Prog. }}$ agora dão a ver a contradição e a falha, pois os

17 Disponível em: http://g1.globo.com/fantastico/noticia/2014/08/eu-tenho-do-dela-diz-goleiro-aranha-sobre-jovem-que-o-ofendeuem-jogo.html. Acesso em: 23 mar. 2018.

18 Mencionado no item (5) SporTV da seção 1 deste artigo.

19 Disponível em: http://sportv.globo.com/site/programas/troca-de-passes/noticia/2017/04/aranha-se-irrita-com-pergunta-e-causapolemica-com-insinuacao-sobre-gays.html. Acesso em: 23 mar. 2018.

20 Disponível em: http://sportv.globo.com/site/programas/troca-de-passes/noticia/2017/04/aranha-se-irrita-com-pergunta-e-causapolemica-com-insinuacao-sobre-gays.html. Acesso em: 23 mar. 2018. 
gays, assim como os negros, vivem uma luta diária contra o preconceito para ter seus direitos reconhecidos. Recuperamos a declaração do goleiro Aranha que provocou novamente um embate entre a $\mathrm{FD}_{\text {Prog. }}$ e a $\mathrm{FD}_{\text {Conserv. }}$ :

EDO7: Não. Tenho treinado, tenho treinado. É que às vezes tem cara, tem jornalista, que gosta de homem, gosta de homem sarado, gosta de cara que tira a camisa, fica mostrando o abdômen. Respeito a opção sexual de cada repórter, mas estou tranquilo. Estive aqui no Palmeiras, o Palmeiras tem um setor de fisiologia ótimo, sempre estive dentro dos padrões, não sou nenhum garoto, mas sempre tive dentro do padrão limite, aceitável para a prática do futebol, tanto que passei sete anos praticamente em time grande - respondeu ${ }^{21}$ (SporTV.com, 22 abr. 2017).

$\mathrm{Na}$ "infelicidade conservadora" do enunciado acima, os gays são generalizados como um grupo de pessoas que se interessa por apenas um tipo de perfil físico. Os que estão acima do peso ou fora de um padrão estético são repelidos pelo gosto gay. Indireta e inconscientemente, deduz-se que "inexistiria amor entre gays", já que o que determina as preferências homossexuais seria, necessariamente, um apelo a um padrão estético-muscular. Não sem razão, os comentaristas do Troca de Passes deram a seguinte contribuição na repercussão do EDO7:

EDO8: Ele, que foi porta-voz, pivô, de uma luta que a gente defende tanto que é tão difícil e dolorida, contra o racismo no futebol, deu uma declaração bastante infeliz [...] Poderia não ter usado essa comparação - disse ${ }^{22}$ (SporTV.com, 22 abr. 2017).

EDO9: Ele tem sido questionado sobre o peso e essa é a resposta irritada dele. Ele tem uma visão deturpada do que é o homossexual, do comportamento do homem homossexual. Não pegou bem a declaração do Aranha, foi mal, foi infeliz. Vai ter tempo de se desculpar, acho que depois de esfriar a cabeça ele pode consertar isso, mas sai mal do jogo da classificação da Ponte ${ }^{23}$ (SporTV.com, 22 abr. 2017).

Efeito de retorno, quem antes foi porta-voz do progresso (cujos enunciados se inscreveram em um $\mathrm{FD}_{\text {Prog. }}$, circunscritos à luta antirracista), hoje caiu, segundo a opinião pública, na "infelicidade" de uma comparação preconceituosa. Para a doxa progressista, o EDO7 revela uma visão deturpada do homossexual e do comportamento homossexual, que não condiz com o estado atual das lutas minoritárias. A contradição é constitutiva dos discursos, conforme afirmavam Pêcheux (1997) e Courtine (2009). Seu time conseguiu a classificação, mas Aranha "saiu mal do jogo da classificação" (EDO9). Um outro site de notícias repercutiu o EDO7 da seguinte forma:

21 Declaração do goleiro Aranha quando perguntado sobre sua forma física. Disponível em: http://sportv.globo.com/site/programas/ troca-de-passes/noticia/2017/04/aranha-se-irrita-com-pergunta-e-causa-polemica-com-insinuacao-sobre-gays.html. Acesso em: 23 mar. 2018.

22 Análise do comentarista Tiago Maranhão a respeito da declaração do goleiro. Disponível em: http://sportv.globo.com/site/ programas/troca-de-passes/noticia/2017/04/aranha-se-irrita-com-pergunta-e-causa-polemica-com-insinuacao-sobre-gays.html. Acesso em: 23 mar. 2018.

23 Análise do comentarista Marcelo Barreto a respeito da declaração do goleiro. Disponível em: http://sportv.globo.com/site/ programas/troca-de-passes/noticia/2017/04/aranha-se-irrita-com-pergunta-e-causa-polemica-com-insinuacao-sobre-gays.html. Acesso em: 23 mar. 2018. 
(8) Blasting News ${ }^{24}$ (blastingnews.com, 23 abr. 2017)

Vitima de racismo, goleiro Aranha faz comentário homofóbico.

(9) Blasting News ${ }^{25}$ (blastingnews.com, 23 abr. 2017)

Em 2014, Aranha mobilizou o país após ter sido chamado de "macaco" por jovem.

$\mathrm{O}$ antes e o agora estão colados e inscritos na história. O olho que tudo vê das câmeras constrói o todo da narrativa e evidencia a falha. A $F D_{\text {Prog. }}$ perde sua pureza ao mostrar que não é intacta, conforme já apontava Courtine (2009). A crença na aliança e na união de determinadas classes - nesse caso, aquelas consideradas minoritárias - deixa ver a falha e emerge a ruptura no ritual da coesão.

Está estabelecida a divisão. A prestação de contas entra em cena na mídia e a cobrança pela coerência faz sua aparição. Como uma vítima de preconceito pode fazer uma afirmação preconceituosa? Apoiados no primado da contradição dos discursos, entendemos que deriva dessa contradição um efeito de sentido de que uma aliança foi traída; o progresso $\left(\mathrm{FD}_{\text {Prog. }}\right)$ cedeu espaço ao conservadorismo $\left(\mathrm{FD}_{\text {Conserv. }}\right)$. O enunciado dividiu-se.

Não estamos interessados na pessoa do goleiro Aranha, mas no discurso que torna a figura do goleiro superficie de um processo de subjetivação. A individualidade do locutor empírico não interessa ao discurso, mas sim a interferência do conservadorismo nos ideais de progresso atribuídos à inserção das diferenças no quadro da igualdade democrática que marca o "non sens do sujeito dividido" (PÊCHEUX, 1997, p. 300). O sujeito é apenas o ponto de apoio da discursividade - princípio de agrupamento e evidência de uma dispersão - e não objeto de investigação.

Pelo funcionamento do inconsciente - aquilo que falha no discurso -, Pêcheux ${ }^{26}$ (1997) trabalha com um postulado que remete a algo que Foucault também defendia a seu modo: a coerência de uma FD não está submetida às leis do pertencimento a uma classe ou a uma consciência ideológico-politica. O discurso não se deixa domesticar pela união, por alianças ou por uma coerência interna (por exemplo, progressista, favorável às lutas das minorias) que pertenceria inequivocamente a um grupo que luta contra a repressão de um outro (por exemplo, conservador e contrário às lutas minoritárias). Antes, está sempre aquém e além das vontades individuais e das decisões consentidas. Suscetivel a falhas, para Pêcheux (1997), e entendido como espaço de microlutas, para Foucault (2004), a compreensão do discurso exige a saída do espaço da coerência e a desidentificação com uma classe: "Ninguém pode pensar do lugar de quem quer que seja: primado prático do inconsciente, que significa que é preciso suportar o que venha a ser pensado, isto é, 'ousar pensar por si mesmo" (PÊCHEUX, 1997, p. 304). Ou, segundo Foucault (2001, p. 148), “[...] não sou dos que tentam limitar os efeitos de poder ao nivel da ideologia”.

24 Disponível em: http://br.blastingnews.com/esporte/2017/04/vitima-de-racismo-goleiro-aranha-faz-comentario-homofobico-00164 6811.html. Acesso em: 23 mar. 2018.

25 Disponível em: http://br.blastingnews.com/esporte/2017/04/vitima-de-racismo-goleiro-aranha-faz-comentario-homofobico-0016 46811.html. Acesso em: 23 mar. 2018.

26 Este texto marca, de certa forma, uma ruptura com a ideia de "máquina discursiva" (e a consequente concepção homogeneizante da FD) construída em trabalhos anteriores do autor. 


\section{ConClusão}

Nossa análise buscou evidenciar as condições político-ideológicas que levaram à identificação entre a fala do goleiro Aranha e sua repercussão midiática, em 2014, e a desidentificação entre a fala do goleiro e sua repercussão midiática em 2017.

A partir do corpus selecionado e analisado, concluímos que o discurso de aliança - deduzido da $\mathrm{FD}_{\text {Prog. }}$ - responsável pelo antirracismo em 2014 sofre uma quebra de expectativa - pelo atravessamento da $\mathrm{FD}_{\text {Conserv. }}$ - em 2017. O processo de midiatização aponta para as contradições no interior de uma suposta homogeneidade/consenso na $\mathrm{FD}_{\text {Prog. }}$ A articulação entre fala do goleiro vs. cobertura midiática é o que evidencia o descompasso e instaura a heterogeneidade no interior dessa mesma $\mathrm{FD}_{\text {Prog. }}$ nos dois momentos considerados.

Os enunciados produzidos em 2017 - tanto as falas do goleiro quanto sua repercussão midiática - dão alguma medida de que o funcionamento discursivo não se dá pela homogeneidade das lutas comuns ou pela identificação de "quem é o meu próximo". O discurso é tudo aquilo que nos escapa e está sempre aberto à desunificação. A contradição evidenciada em nossa análise - Aranha/mídia em 2014 versus Aranha/mídia em 2017 - permite a relativização da ideia de aliança ou de união como ritual sem falha em que a coerência ou a fidelidade seriam a argamassa.

Nesse sentido, o caso Aranha é entendido como sintoma de algo mais amplo que diz respeito ao funcionamento dos discursos e não à "incoerência individual" do goleiro. Entendemos, com Pêcheux (1997, p. 304), que é preciso, no que diz respeito às lutas ${ }^{27}$, "ousar pensar por si mesmo". E isso envolve, não sem riscos, algumas coragens teórico-práticas: 1 . de não vincular o que se pensa, necessariamente, a uma causa coletiva (massificada na/pela mídia); 2. de não jurar fidelidade a uma ideologia ou a um partido político; 3. de perceber que os efeitos da discriminação e do preconceito não são exclusividade de uma classe, mas algo muito mais difuso a que os sujeitos estão submetidos. O dispositivo teórico-analítico, dessa forma, deve estar aberto a todas as possibilidades de combinação ou, ao menos, ao máximo de suas possibilidades.

\section{THE Midiatic CONSTRUCTION OF PREJUDICE: A CASE OF CONTRADICTION IN SPORTS JOURNALISM}

Abstract: This paper aims to analyze the enunciative contradictions presented in the media regarding the alliance discourse. This discourse will be problematized through the theoretical assumptions of Discourse Analysis. We composed a corpus of utterances (re) produced by the media in the context of two polemics: 1. the case of racism against a soccer goalkeeper named Aranha, in 2014; 2 . the most recent case, in which the same soccer goalkeeper was built in the media as guilty of homophobia, in 2017.

Keywords: Sports journalism. Discourse analysis. Media construction. Divided statement. Discursive formation.

27 Não defendemos a invalidade ou ineficácia das lutas coletivas. Tampouco somos contrários a elas. O que propomos é que a ideia de "causa" ou "luta coletiva" produz um efeito ideológico de que nessa esfera todos são iguais e lutam por um ideário comum. 


\section{REFERÊNCIAS}

COURTINE, J.-J. Análise do discurso politico: o discurso comunista endereçado aos cristãos. Tradução Cristina Birck et al. São Carlos: EDUFSCAr, 2009.

DUNKER, C. Mal-estar, sofrimento e sintoma: uma psicopatologia do Brasil entre muros. São Paulo: Boitempo, 2015.

FOUCAULT, M. Poder-corpo. In: FOUCAULT, M. Microfisica do poder. 16. ed. Tradução e organização Roberto Machado. Rio de Janeiro: Edições Graal, 2001. p. 145-152.

FOUCAULT, M. A arqueologia do saber. 7. ed. Tradução Luiz Felipe Baeta Neves. Rio de Janeiro: Forense, 2004.

PÊCHEUX, M. Só há causa daquilo que falha ou o inverno político francês: início de uma retificação. In: PECCHEUX, M. Semântica e discurso: uma crítica à afirmação do óbvio. 3. ed. Tradução Eni Orlando et. al. Campinas: Pontes, 1997. p. 293-307.

PÊCHEUX, M. O estranho espelho da análise do discurso. In: COURTINE, J.-J. Análise do discurso político: o discurso comunista endereçado aos cristãos. Tradução Cristina Birck et al. São Carlos: EDUFSCAr, 2009. p. 21-26. 